\title{
The Spatial Pattern of the Upper Limit of Montane Deciduous Broad-Leaved Forests and Its Geographical Interpretation in the East Monsoon Realm of China
}

\author{
Jing Wang ${ }^{1,2} \mathbb{D}$, Baiping Zhang ${ }^{1, *}$ and Yonghui Yao ${ }^{1} \mathbb{D}$ \\ 1 State Key Lab for Resources and Environment Information System, Institute of Geographic Sciences and \\ Natural Resources Research, Chinese Academy of Sciences, Beijing 100101, China; \\ wangj.16b@igsnrr.ac.cn (J.W.); yaoyh@lreis.ac.cn (Y.Y.) \\ 2 University of Chinese Academy of Sciences, Beijing 100049, China \\ * Correspondence: zhangbp@1reis.ac.cn
}

check for updates

Citation: Wang, J.; Zhang, B.; Yao, Y. The Spatial Pattern of the Upper Limit of Montane Deciduous Broad-Leaved Forests and Its Geographical Interpretation in the East Monsoon Realm of China. Forests 2021, 12, 1225. https://doi.org/10.3390/f12091225

Academic Editor: Laszlo Erdos

Received: 22 July 2021

Accepted: 7 September 2021

Published: 9 September 2021

Publisher's Note: MDPI stays neutral with regard to jurisdictional claims in published maps and institutional affiliations.

Copyright: (c) 2021 by the authors. Licensee MDPI, Basel, Switzerland. This article is an open access article distributed under the terms and conditions of the Creative Commons Attribution (CC BY) license (https:// creativecommons.org/licenses/by/ $4.0 /)$.

\begin{abstract}
Montane deciduous broad-leaved forests (MDB) are mainly distributed in the east monsoon realm of China. The upper limit of MDB significantly varies from mountain to mountain. However, the spatial pattern of the upper limit of MDB and its underlying drivers are still unknown. In this study, we conducted hierarchical multiple regression to quantify the effect of climatic factors, peak elevation, and cold tolerance of dominant species on the geographical distribution of the upper limit of MDB on 75 mountains in the east monsoon realm of China. The results show that: (1) the upper limit of MDB in the east monsoon realm of China, $2800 \mathrm{~m}$, is the highest in Taibai peak of the Qinling mountain ranges, from where it tends to decrease both northward and southward. (2) The upper limit of MDB on the mountains with climatic treeline is mainly affected by climatic factors, the minimum temperature of the coldest month (MinT), and the precipitation seasonality (PS), with an $\mathrm{R}^{2}$ of 0.733 . (3) The upper limit of MDB on both temperate and subtropical mountains without climatic treeline is affected by MinT, PS, peak elevation, and cold tolerance of dominant species together, with an $\mathrm{R}^{2}$ of 0.793 and 0.748 , respectively. (4) The dominant species of the upper limit of MDB significantly differ temperate and subtropical ranges, the former of which is mainly in the genus Betula, and the latter of which is in the genus Quercus. The upper limit of MDB with the genus Fagus as dominant species is only distributed in the mountains towards the south of the Qinling mountain ranges. (5) The warmth index (WI) at the upper limit of deciduous broad-leaved forest on the mountains with climatic treeline is about $60^{\circ} \mathrm{C}$ month, which is lower than that at the northernmost boundary of the latitudinal distributed deciduous broad-leaved forest $\left(90{ }^{\circ} \mathrm{C}\right.$ month). Our study revealed the spatial pattern and geographical drivers of the upper limit of MDB, improved our understanding of differences in MDB vegetation among different mountain ranges, and provided climatic correlates for predicting the dynamics of the upper limit of MDB under climate change.
\end{abstract}

Keywords: upper limit; montane deciduous broad-leaved forest; mountain climate; dominant species composition; peak elevation; China

\section{Introduction}

The deciduous broad-leaved forest is an important vegetation zone in China, with different structure and ecological functions from other vegetation types [1]. For example, the deciduous broad-leaved forests are associated with a higher carbon sequestration rate than conifer forests, and their water storage capacity is higher than that of evergreen broad-leaved forests [2,3]. Previous studies have been carried out focusing on the effect of climate on the latitudinal distribution of deciduous broad-leaved forests. However, the altitudinal distribution of deciduous broad-leaved forests on mountains has rarely been explored [4-6]. The monsoon region in the Eastern China has developed many montane deciduous broad-leaved forest (MDB) belts due to its significant climatic gradient, 
numerous mountains, and complex topography $[7,8]$. It has become an ideal area for exploring the pattern and drivers of the upper limit of MDB, since the species richness of MDB in the east monsoon realm of China is higher than that in America and Europe [1,9]. As a critical boundary of the altitudinal mountain vegetation distribution, the upper limit of MDB can reflect the adaptation of dominant deciduous broad-leaved species to the mountain environment [9]. The upper limits of MDB have been lifted upward through expanding thermophilic deciduous broad-leaved species and contracting cold-adapted conifers under global warming [10]. Elevation variations of the upper limits of MDB can have influences on the structure and function of mountain ecosystem [11]. To accurately predict the dynamics of the upper limit of MDB as well as maintain the stability of mountain vegetation structure and the ecological functional sustainability of the mountain ecosystem, factors that affect the pattern of the upper limit of MDB need to be explored.

Previous research found that mountain climate was usually a dominant factor affecting the geographical distribution of the upper limit of MDB on mountains with climatic treeline at the regional scale [12-14]. Specifically, low temperature is a limiting factor to control the elevation of the limits of montane vegetational belts $[13,15]$. It is well known that the air temperature decreases with altitude in mountains, and deciduous broad-leaved species cannot survive in higher elevations due to freezing injury [15]. Thus, the deciduous broadleaved forest is replaced by conifer forest, forming the upper limit of MDB. Meanwhile, mean annual precipitation also affects the distribution of montane vegetational belts, due to the significantly differential drought tolerance of dominant species of different vegetation types. The mean annual precipitation in the deciduous broad-leaved forest ranges from 600 to $1000 \mathrm{~mm}$ [16]. The mean annual precipitation in the eastern monsoon region of China is $600-1500 \mathrm{~mm}$ [17]. It is suggested that the mean annual precipitation of the east monsoon region of China is sufficient to support the growth of deciduous broad-leaved forests. There are two climatic zones (temperate zone and subtropical zone) in the east monsoon region of China. The dominant species of MDB in both temperate and subtropical mountains are different along latitudinal gradients [1]. Xu (2003) proposed that the differences in dominant species of the deciduous broad-leaved forest within different climatic zones is probably due to the influence of precipitation seasonality (PS), to which deciduous broad-leaved species are more sensitive, rather than by mean annual precipitation $[8,18]$. However, the influence of PS on the spatial pattern of the upper limit of MDB in the east monsoon region of China is still unknown.

Although mountain climate can directly affect the upper limit of MDB, peak elevation, which is one of the topographical factors, also plays an essential role in controlling the elevation of the upper limit of MDB on mountains without climatic treeline at a regional scale. A certain elevation of mountains is needed to form a climatic treeline ensuring the full development of montane vegetational belts [19,20]; when the actual treeline on mountains is close to the climatic treeline, the margins of montane vegetational belts reach the thermal limitation (or climatic limitation) [21,22]. Otherwise, the summit syndrome can depress the limit of montane vegetational belts, lowering elevations if the actual treeline is far below the climatic treeline [19]. Similarly, the upper limit of MDB is necessarily compressed by the summit syndrome caused by strong wind and poor soil on the summit as well. It is demonstrated that with an insufficient peak elevation, the upper limit of MDB cannot reach the climatic threshold, forming a false upper limit of MDB, even if the climate condition of the mountain summit meets the growth requirement of deciduous broad-leaved species. Therefore, the upper limit of MDB on the mountain without climatic treeline is affected by the combined effects of mountain climate and peak elevation. However, no study has quantified their relative contribution to the upper limit of MDB. The main factors causing the upper limit of deciduous broad-leaved forest on the mountains without climatic treeline are still unclear. 
A previous study found that the warmth index (WI) can reflect the cumulative temperature demands of vegetation types and indicated that the WI at the northern boundary of the latitudinal distribution of deciduous broad-leaved forest is $90^{\circ} \mathrm{C}$ month [23]. Wu (1983) found that the composition of dominant species in the deciduous broad-leaved forest is different along the latitudinal and altitudinal distributions in the eastern monsoon region of China [1]. Furthermore, the cold tolerance of deciduous broad-leaved species varies greatly [15]. Therefore, the WI at the upper limit of MDB might be different from that at the northern boundary of the deciduous broad-leaved forest. In other words, the upper limit of deciduous broad-leaved forest on the mountain without climatic treeline can also be adjusted by the cold tolerance of dominant species at the local scale. However, to what extent the cold tolerance of dominant species can affect the pattern of the upper limit of MDB in the east monsoon realm of China has not been investigated.

In this study, we aimed to (1) explore the spatial pattern of the upper limit of deciduous broad-leaved forest on the mountains with climatic treeline and its underlying drivers; (2) explore the spatial pattern of the upper limit of deciduous broad-leaved forest on the mountains without climatic treeline, and quantify the effects of climatic factors, peak elevation, and cold tolerance to dominant species on such a pattern; (3) identify the WI at the upper limit of MDB; and (4) investigate the different dominant species of the upper limit of deciduous broad-leaved forest on temperate and subtropical mountains in the east monsoon realm of China. Findings from this study can improve the understanding of differences in deciduous broad-leaved forests among different mountain ranges, and provide climatic correlates for predicting the dynamics of the upper limit of MDB under climate change.

\section{Data and Methods}

\subsection{Data Sets for $M D B$}

Data sets for the altitudinal distribution of deciduous broad-leaved forest were assembled by reviewing ecological and geographical journals, books, and scientific investigation reports to record the geographical information, lower and upper elevational limits, and associated information (e.g., peak elevation, dominant species, and community characteristics) for each mountain with MDB reported. Specifically, we developed the data sets according to the following criteria: (1) Limits of MDB were excerpted from vegetation investigation on mountains seldom disturbed, which can reflect the pattern of natural montane vegetation; (2) Dominant species were distinguished from the altitudinal limits of MDB [1,17]; (3) The base belts of mountains were defined by zonal vegetation [21]. Overall, we extracted a total of 75 upper limits of MDB from the above data sets (Tables S1-S3, and Reference list in supplementary material). The upper limits of these MDBs were mainly distributed, from north to south, in Changbai Mts, Yanshan Mts, Taihang Mts, Lvliang Mts, Qinling Mts, Daba Mts, Dabie Mts, Wuyi Mts, and Xuefeng Mts in the east monsoon realm of China (Figure 1).

The upper limits of MDB in this study can be classified into two types according to whether there is a climatic treeline or not. The upper limits of deciduous broad-leaved forest on the mountains with climatic treeline are mainly affected by climatic factors, while those without climatic treeline are affected by climate, peak elevation, and cold tolerance of dominant species. To be specific, the upper limit of MBD on the mountains with climatic treeline can fully develop to the climatic threshold. Only 8 upper limits were included for this type in the east monsoon realm of China, which belong to UMDB (I) (Figure 2). If the actual treeline of mountains are lower than climatic treeline, summit syndrome can depress the upper limit of MDB, and such upper limits of MBD cannot develop to their climatic threshold. A total of 67 upper limits were included for this type in the east monsoon realm of China, which belong to MDB (II). Based on the climate boundary between temperate zone and subtropical zone [24], the upper limit of MDB on mountains without climatic treeline in the east monsoon realm of China was further divided into two categories: 45 upper limits of MDB on temperate mountains without climatic treeline, 
which belong to TMDB (II), and 22 upper limits of MDB on subtropical mountains without climatic treeline, which belong to SMDB (II).

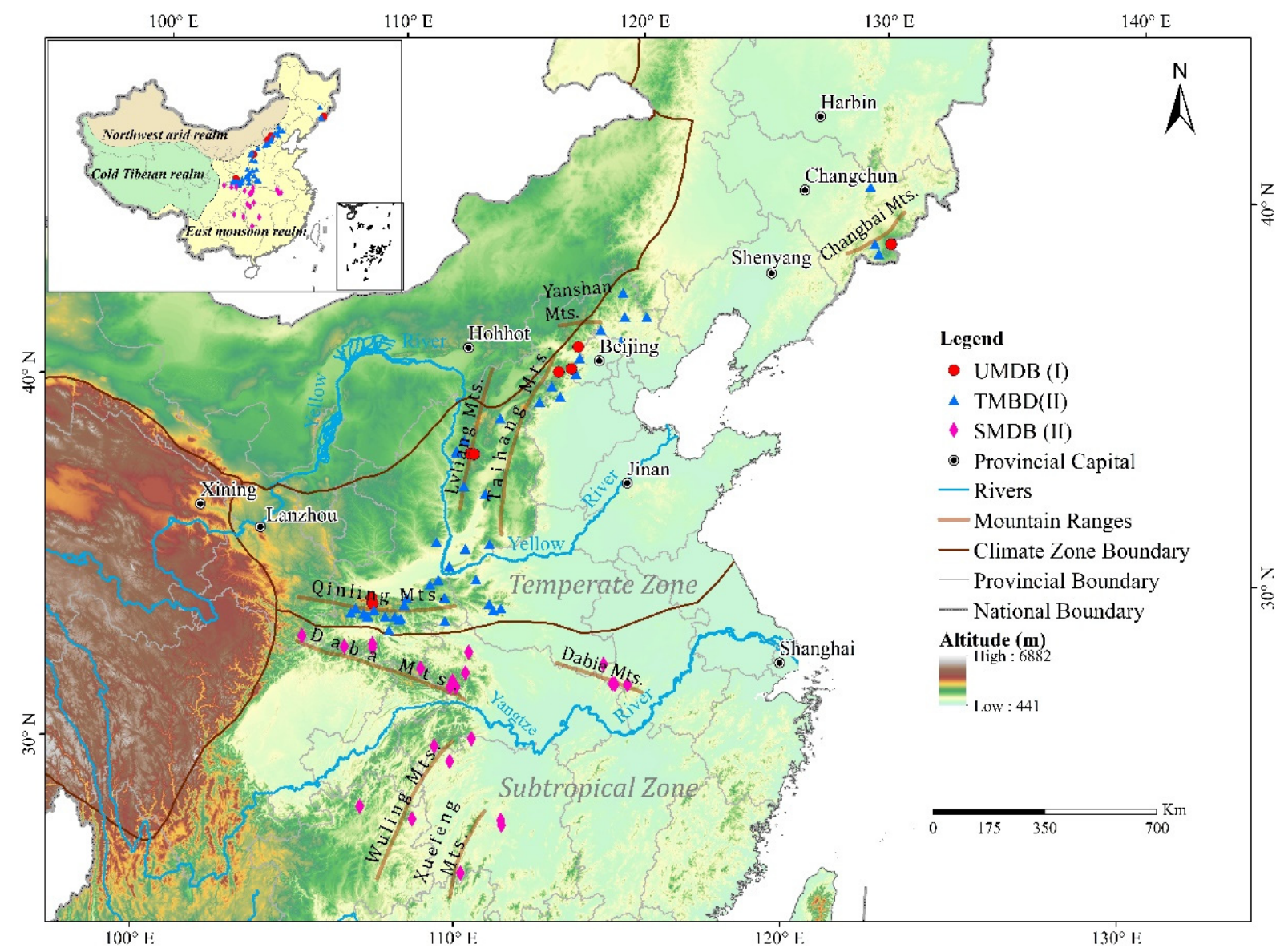

Figure 1. The upper limit of montane deciduous broad-leaved forest in the east monsoon realm of China. Abbreviation: UMDB (I), 8 upper limits of deciduous broad-leaved forest on the mountains with climatic treeline; TMDB (II), 45 upper limits of deciduous broad-leaved forests on the temperate mountains without climatic treeline; SMDB (II), 22 upper limits of deciduous broad-leaved forest on the subtropical mountains without climatic treeline.

\subsection{Environmental Data}

Environmental data were composed of climatic variables, topographical variable (peak elevation), and dominant species in this study. The climatic variables included the minimum temperature of the coldest month (MinT) and PS. MinT is usually used as a surrogate for the low temperature, limiting the upward extension of the deciduous broad-leaved forest [15]. PS was defined as the ratio of the standard deviation of the monthly total precipitation to the mean monthly total precipitation, which is not affected by elevation, as indicated by previous studies $[25,26]$. These climatic parameters that were matched with MDB were extracted from the World Climate Version 2.0 database based on the geographical location of mountains with MDB $[27,28](30$ arc seconds; http:/ / worldclim.org/, accessed date 5 January 2021). Both the peak elevation of the mountain with MDB and the composition of dominant species of MDB were derived from the above data sets. 


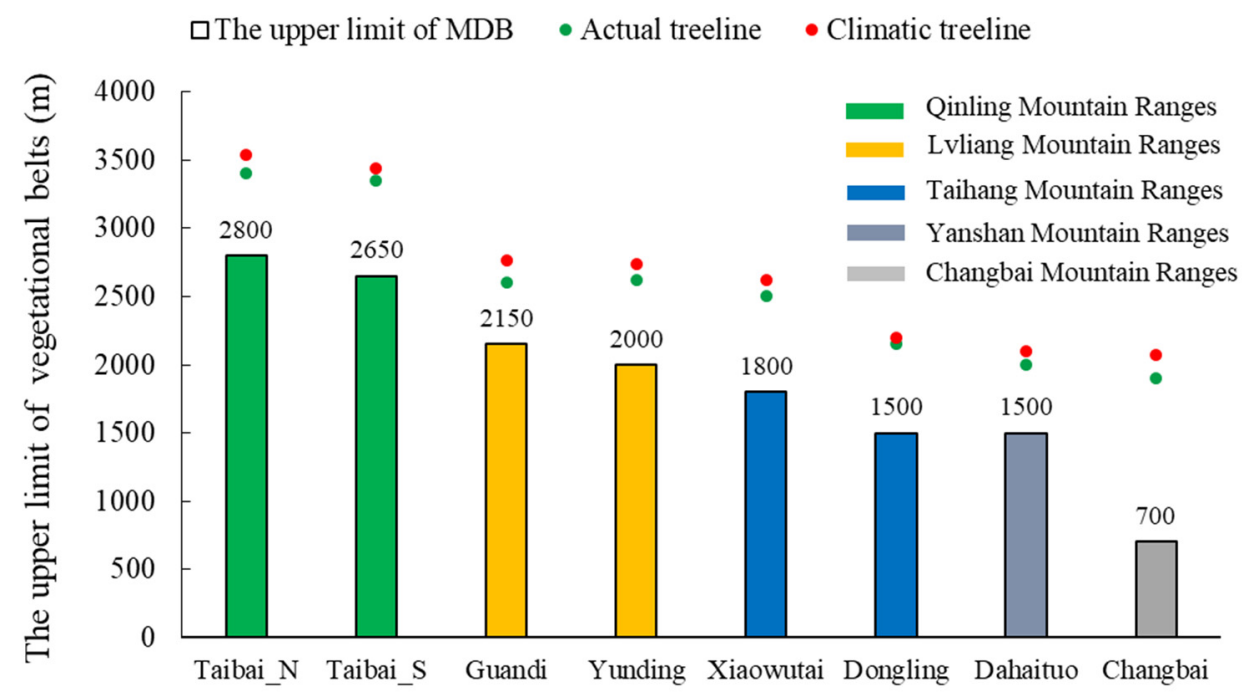

Figure 2. The upper limit of deciduous broad-leaved forest on the mountains with climatic treeline in the east monsoon realm of China. Each bar represents the upper limit of the deciduous broad-leaved forest on the mountains with climatic treeline in the east monsoon realm of China. The different colors of the bars represent different mountain ranges. The red point indicates the elevation of the climatic treeline on the mountains with deciduous broad-leaved forest. The green point indicates the altitude of the actual treeline on the mountains with deciduous broad-leaved forest. Abbreviation: Taibai-S, the south slope of the Taibai mountain; Taibai-N, the north slope of the Taibai mountain.

\subsection{Statistical Analyses}

WI has been widely used to reveal the thermal characteristics of deciduous broadleaved forests, since different dominant species of deciduous broad-leaved forest are associated with significantly differential tolerance towards cold. To calculate the WI of MDB accurately in different mountain ranges, the altitudinal lapse rate of temperature (ALRT) of different mountain ranges was firstly calculated by the following Equation (1) based on meteorological station data (http:/ / data.cma.cn, accessed date 19 February 2021). This method has been used to calculate the air temperature characteristics at different altitudes on the mountains [29]. The monthly mean temperature at the limits of MDB on different mountain ranges was estimated by Equation (2). Then, the WI of the limits of MDB on different mountain ranges was calculated by Equation (3), as proposed by Kira [23].

$$
\begin{gathered}
\mathrm{Y}=\mathrm{a}_{0}+\mathrm{a}_{1} \times \mathrm{X} 1+\mathrm{a}_{2} \times \mathrm{X} 2 \\
\mathrm{Ti}=\mathrm{T}_{0}+\left(\mathrm{H}_{1}-\mathrm{H}_{0}\right) \times \text { ALRT } \\
\mathrm{WI}=\sum_{i=1}^{12}(\mathrm{Ti}-5) \text { foreachmonthinwhichTi }>5{ }^{\circ} \mathrm{C}
\end{gathered}
$$

$\mathrm{Y}, \mathrm{X} 1$, and $\mathrm{X} 2$ represent monthly mean temperature $\left({ }^{\circ} \mathrm{C}\right)$, latitude, and altitude, respectively. The symbols $\mathrm{a}_{0}, \mathrm{a}_{1}$, and $\mathrm{a}_{2}$ are regression coefficients, while $\mathrm{a}_{2}$ is for ALRT. $\mathrm{T}_{0}$ represents the monthly mean temperature $\left({ }^{\circ} \mathrm{C}\right)$ of meteorological stations on different mountain ranges. $\mathrm{H}_{0}$ represents the elevation of a meteorological station on different mountain ranges above sea level. $\mathrm{H}_{1}$ represents the altitude of the limits of MDB. Ti represents the monthly mean temperature at the limits of the montane deciduous broad-leaved forest $\left({ }^{\circ} \mathrm{C}\right)$.

Pearson correlational analysis was developed to explore relationships between the upper limit of MDB and latitude, longitude, MinT, PS, or peak elevation. Then, a linear regression model and a curvilinear regression model were developed to examine to what extent the upper limit of MDB was influenced by latitude, longitude, MinT, PS, and peak elevation. Finally, hierarchical multiple regression was conducted to reveal the effects of MinT, PS, peak elevation, and the cold tolerance of species dominating the upper limit of 
MDB on the patterns of the upper limit of MDB in the east monsoon realm. Independent variables were MinT, PS, peak elevation $(\mathrm{H})$, and cold tolerance of dominant species of the upper limit of MDB. The cold tolerance of dominant species was regarded as an ordinal variable in the hierarchical multiple regression model, and the rank, from 1 to 8 , was estimated by the MinT at the upper limit of MDB. The lower the MinT at the upper limit of MDB, the greater the cold tolerance of deciduous broad-leaved species, and the larger the rank of this species in the hierarchical multiple regression model. In this study, the rank order of Betula utilis D.Don in the hierarchical multiple regression is the maximum, 8 , in the hierarchical multiple regression; the rank order of species belonging to the Fagus genus is the minimum, 1 , in the hierarchical multiple regression. The dependent variable was the upper limit of MDB. All statistical analyses were performed by using SPSS 24.0 software.

\section{Results}

\subsection{Geographical Distribution of the Upper Limit of MDB in the East Realm of China}

As the latitudinal and longitudinal gradient commonly reflect temperature and precipitation gradient, the geographical distribution of the upper limit of MDB can indirectly reflect the effect of climate on the upper limit of MDB. Our results showed that on the mountains with climatic treeline, the upper limit of MDB was strongly influenced by latitude and longitude, and the coefficient of determination of linear regression model were 0.95 and 0.91 , respectively $(p<0.01)$. On the mountains without climatic treeline, the upper limit of MDB showed a quadratic curve pattern at the latitudinal gradient, which peaked at near $33^{\circ} \mathrm{N}$, and the coefficient of determination of the curvilinear regression model was $0.43(p<0.001)$; it showed a negative linear relationship with longitude, which decreased with the longitude, and the coefficient of determination was $0.58(p<0.001)$ (Figure 3$)$.
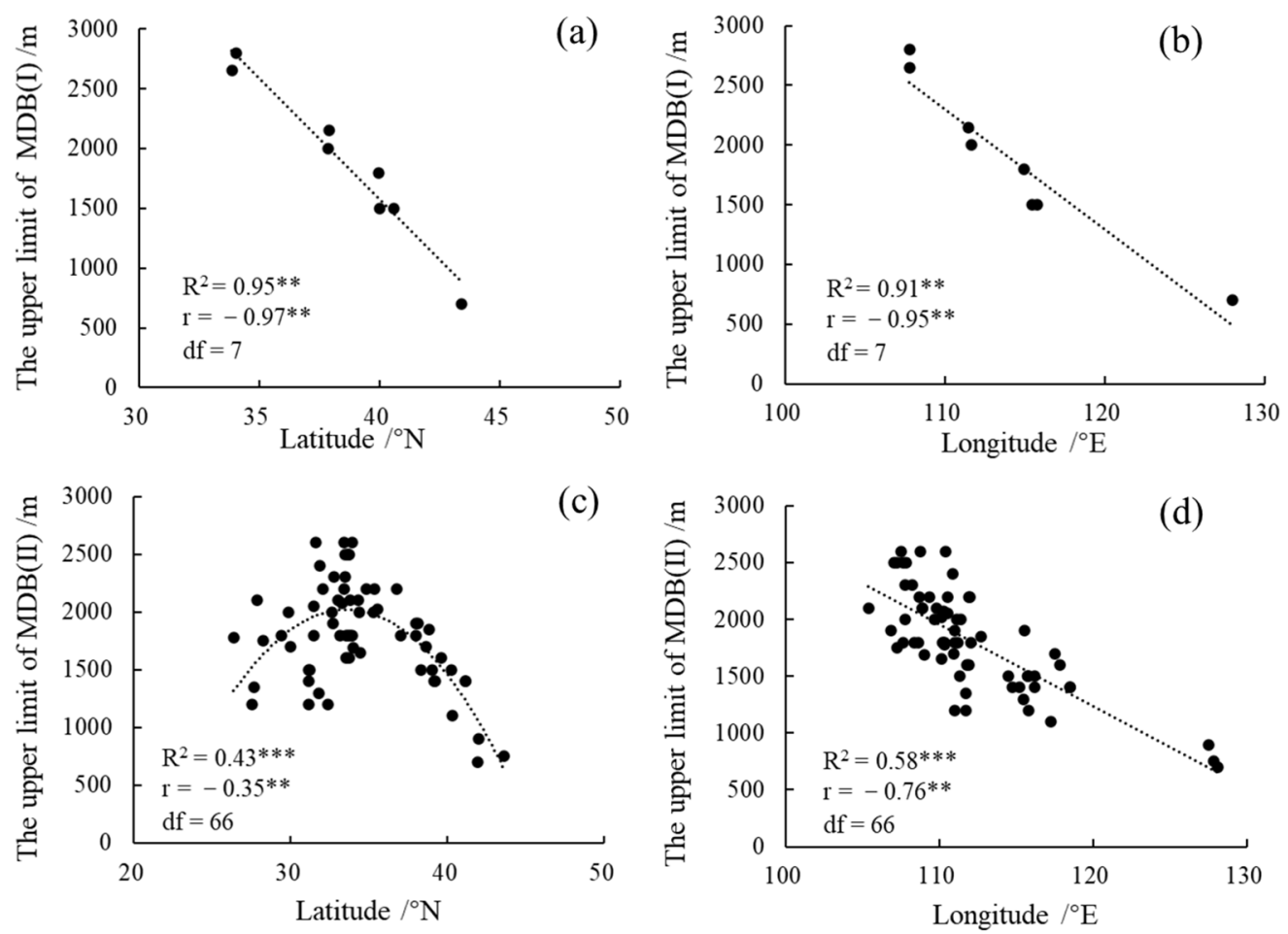

Figure 3. The relationship between the upper limit of MDB and latitude or longitude and the results of regression analysis, $(\mathbf{a}, \mathbf{b}, \mathbf{d})$ linear, (c), curvilinear. df, degree of freedom. $\mathrm{MDB}(\mathrm{I})$, the upper limits of deciduous broad-leaved forest on the mountains with climatic treeline; $\mathrm{MDB}(\mathrm{II})$, the upper limits of deciduous broad-leaved forests on the mountains without climatic treeline. "r value" represents Pearson correlation coefficient. df, degree of freedom. Note: ${ }^{* *} p<0.01,{ }^{* * *} p<0.001$.

Furthermore, on the mountains without climatic treeline in the temperate climate zone, the results showed that the upper limit of MDB was influenced by latitude and 
longitude in the linear regression model, and the coefficient of determination was 0.59 and 0.70 , respectively $(p<0.001)$. On the mountains without climatic treeline in the subtropical climate zone, the results showed that the upper limit of MDB was not influenced by latitude, while influenced by longitude, which explained a few partitions of the total deviance $\left(R^{2}=0.34, p<0.01\right)$ (Figure 4$)$.
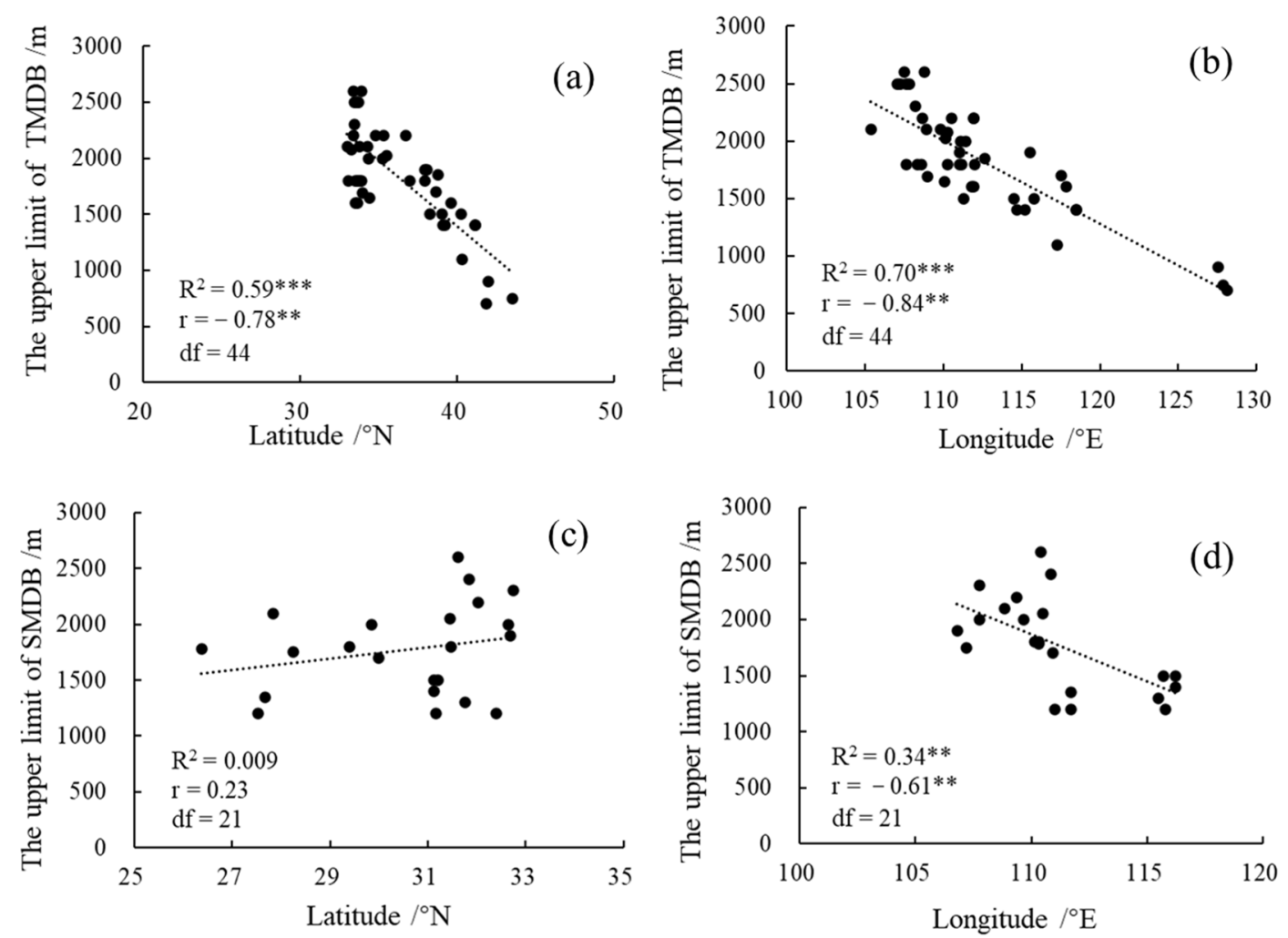

Figure 4. The relationship between the upper limit of MDB and latitude or longitude and the results of regression analysis, $(\mathbf{a}, \mathbf{b})$ on the temperate mountains without climatic treeline, $(\mathbf{c}, \mathbf{d})$ on the subtropical mountains without climatic treeline. TMDB, deciduous broad-leaved forest on the temperate mountains without climatic treeline; SMDB, deciduous broad-leaved forest on the subtropical mountains without climatic treeline. "r value" represents Pearson correlation coefficient. $d f$, degree of freedom. Note: ${ }^{* *} p<0.01,{ }^{* * *} p<0.001$.

\subsection{The Influence of Climate Factors on the Upper Limit of $M D B$}

On the mountains with climatic treeline, the upper limit of MDB was influenced by MinT and PS, and the coefficient of determination of linear regression model were 0.66 $(p<0.01)$ and $0.40(p<0.05)$, respectively. On the mountains without climatic treeline in the temperate climate zone, the upper limit of MDB was influenced by MinT and PS, and the coefficient of determination of linear regression model were 0.44 and 0.27 , respectively $(p<0.001)$. Meanwhile, on the mountains without the climatic treeline in the subtropical climate zone, the upper limit of MDB was influenced by MinT and PS, and the coefficient of determination of linear regression model were $0.20(p<0.05)$ and $0.27(p<0.01)$, respectively (Figure 5). 

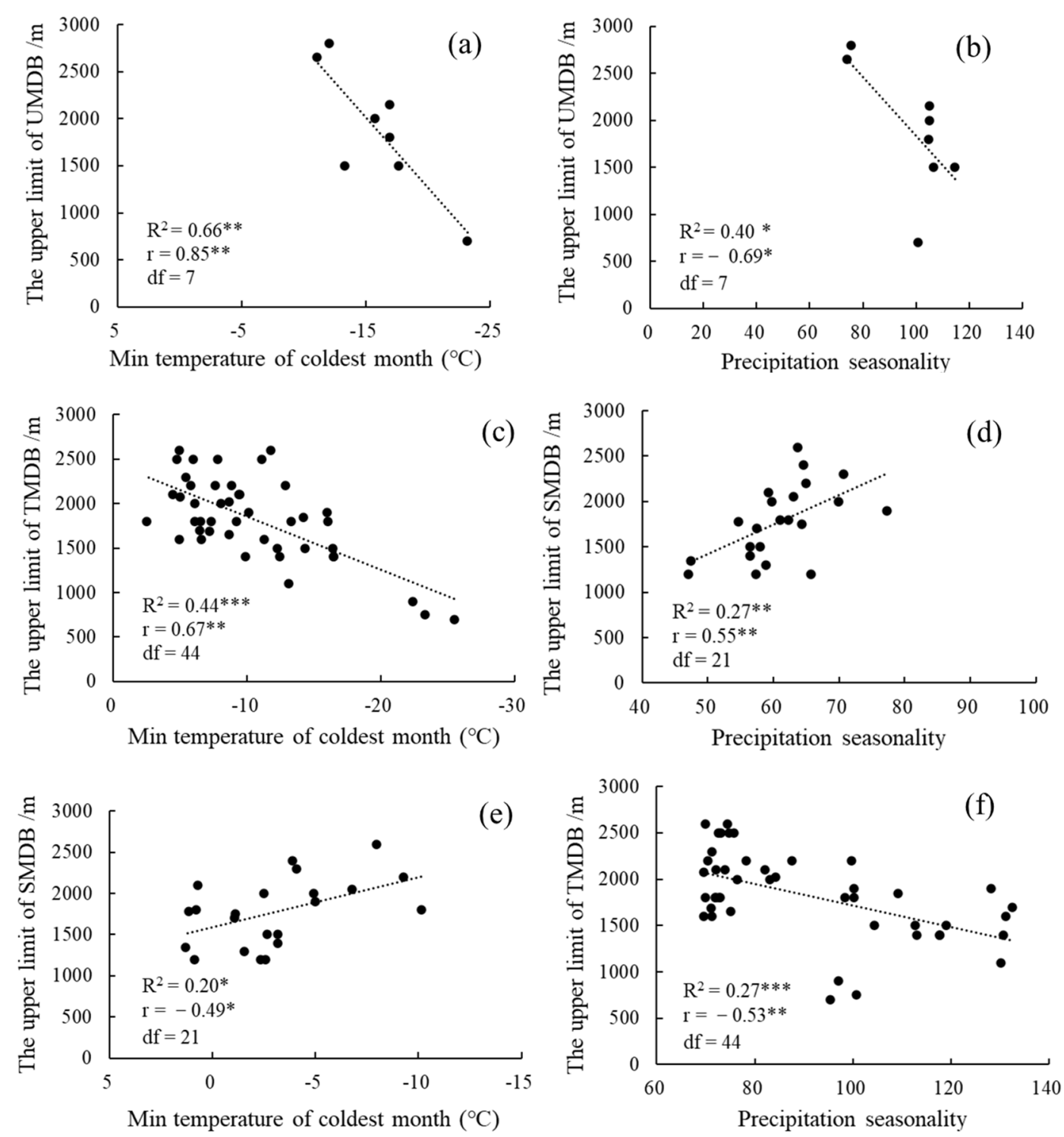

Figure 5. The effect of climate on the upper limit of deciduous broad-leaved forest on the mountains with climatic treeline $(\mathbf{a}, \mathbf{b})$ or without climatic treeline $(\mathbf{c}-\mathbf{f})$. "r value" represents Pearson correlation coefficient. MDB, deciduous broad-leaved forests on the mountains with climatic treeline; UMDB, deciduous broad-leaved forests on the mountains with climatic treeline; TMDB, deciduous broad-leaved forests on the temperate mountains without climatic treeline; SMDB, deciduous broad-leaved forest on the subtropical mountains without climatic treeline. " $\mathrm{r}$ value" represents Pearson correlation coefficient. df, degree of freedom. Note: ${ }^{*} p<0.05,{ }^{* *} p<0.01,{ }^{* * *} p<0.001$.

\subsection{The Influence of Peak Elevation on the Upper Limit of $M D B$}

We found that the upper limits of MDB on the mountains without climatic treeline in both the temperate and subtropical climate zones were influenced by peak elevation, and the coefficient of determination was 0.60 and 0.63 , respectively $(p<0.001)$ (Figure 6). 

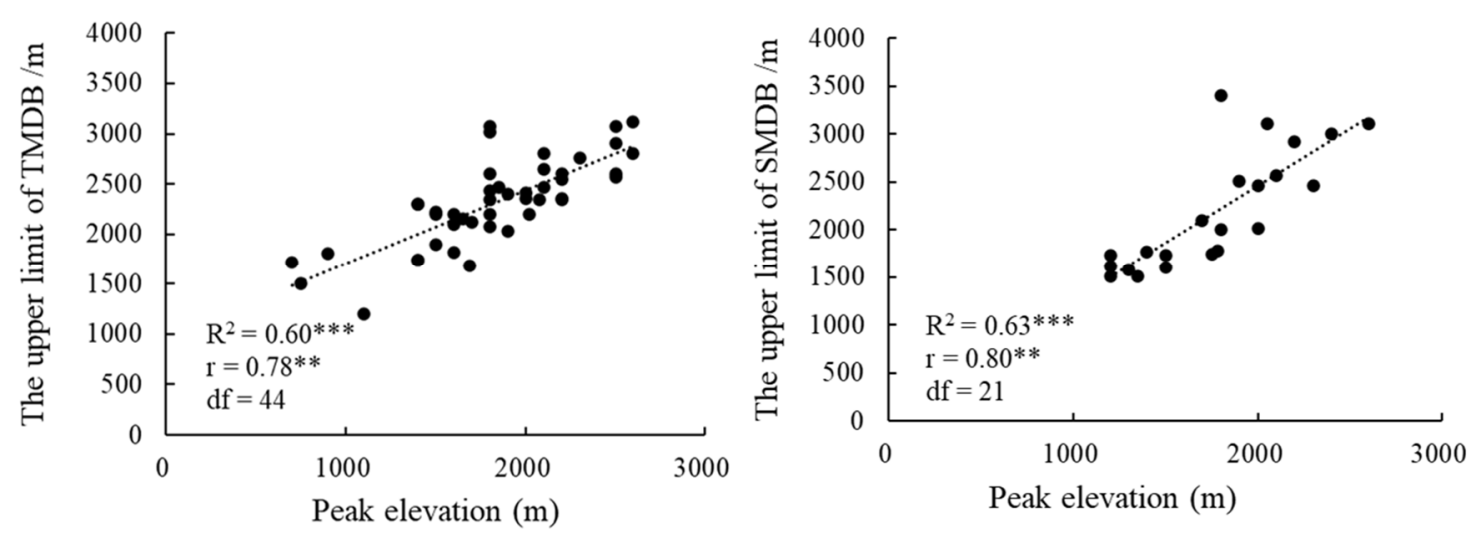

Figure 6. The effect of peak elevation on the upper limit of deciduous broad-leaved forest. TMDB, deciduous broad-leaved forests on the temperate mountains without climatic treeline; SMDB, deciduous broad-leaved forest on the subtropical mountains without climatic treeline. "r value" represents Pearson correlation coefficient. df, degree of freedom. Note: ${ }^{* *} p<0.01,{ }^{* * *} p<0.001$.

\subsection{The Influence of the Cold Tolerance of Dominant Species on the Upper Limit of MDB}

The MinT at the upper limit of MDB can reflect the characteristics of cold tolerance of species dominating the upper limit of MDB. The cold tolerance in dominant species of the upper limit of MDB can be ranked from the highest to the lowest as: Betula utilis D.Don > Betula albosinensis Burkill > Betula platyphylla Sukaczev > Quercus mongolia Fischer ex Ledebour $>$ Quercus wutaishanica Mayr $>$ Quercus aliena var. acutiserrata Maximowicz ex Wenzig > Quercus serrata var. brevipetiolata Murray > Fagus spp. (Figure 7). On the mountains with climatic treeline, the WI at the upper limit of MDB was not less than $60{ }^{\circ} \mathrm{C}$ month, which was lower than that on the mountains without climatic treeline. Comparing the dominant species of the upper limit of MDB on the mountains between the temperate and subtropical zones, the former of which were in the genera Betula and Quercus, while the latter of which were in the genera Fagus and Quercus. Beech forests were only distributed on the subtropical mountains, and the WI at the upper limit of MDB to the south of the Daba mountain ranges, was about $120{ }^{\circ} \mathrm{C}$ month (Figure 8).

\subsection{The Relative Contribution of Environmental Factors to the Upper Limit of MDB}

The results based on hierarchical multiple regression showed that the elevation of the upper limit of MDB on the mountains with climatic treeline was mainly affected by climate factors (MinT and PS), and the coefficient of determination of the regression model was $0.733(p<0.05)$. The elevations of the upper limit of MDB on the mountains without climatic treeline in the temperate and subtropical climate zones were both affected by the climate factors (MinT and PS), topographical factor (peak elevation), and cold tolerance of dominant species; their coefficients of determination of the hierarchical multiple regression model were $0.793(p<0.001)$ and $0.748(p<0.05)$, respectively. To be specific, a three-stage hierarchical multiple regression model was conducted to examine the effects of these three types of factors on the upper limit of MDB of the mountains without climatic treeline in the temperate and subtropical climate zones, respectively. With the input of $\mathrm{H}$ and RCT, $\Delta \mathrm{R}^{2}$ of the hierarchical multiple regression model was significantly $(p<0.05)$ increased. The coefficient of determination of model 3 was the largest and statistically significant, which was the best fit model for the upper limit of MDB on the mountains without climatic treeline in the temperate and subtropical climate zones (Table 1). 


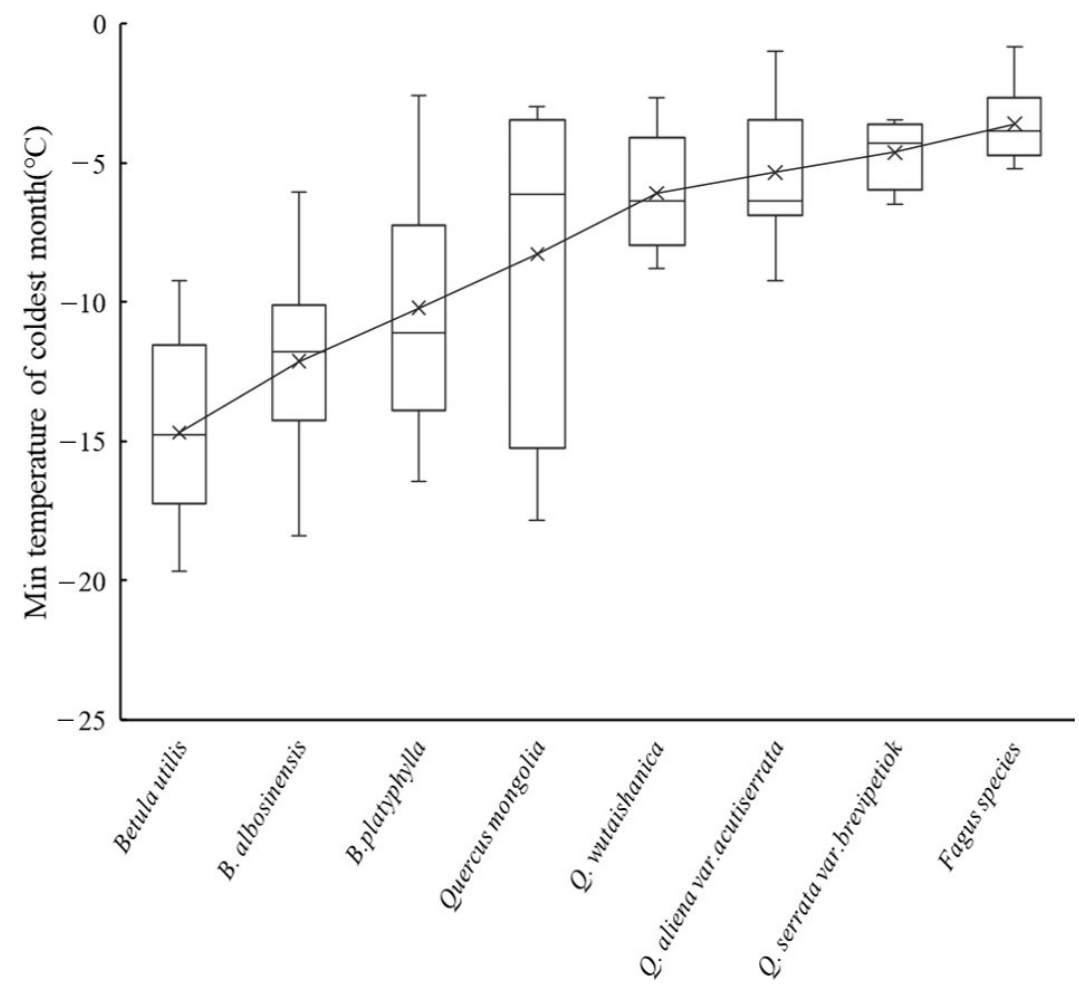

Figure 7. Characteristics of the minimum temperature of the coldest month of species dominating the upper limit of the montane deciduous broad-leaved forest. The line in the boxplot, and the upper and lower whiskers of the boxplot represent the median, interquartile range (from 1st to 3rd quartile). " $x$ " in the boxplot represents the average of the minimum temperature of coldest month at the upper limit of MDB with same dominant species. "Fagus spp." in the graph represents the dominant species of overall beech forest on the subtropical mountains, belonging to the genus Fagus. In the study, we did not show the characteristics of the minimum temperature of the coldest month for each species belonging to the genus Fagus, because the site number of each species belonging to the genus Fagus was less than 5, which was insufficient to generate boxplots.

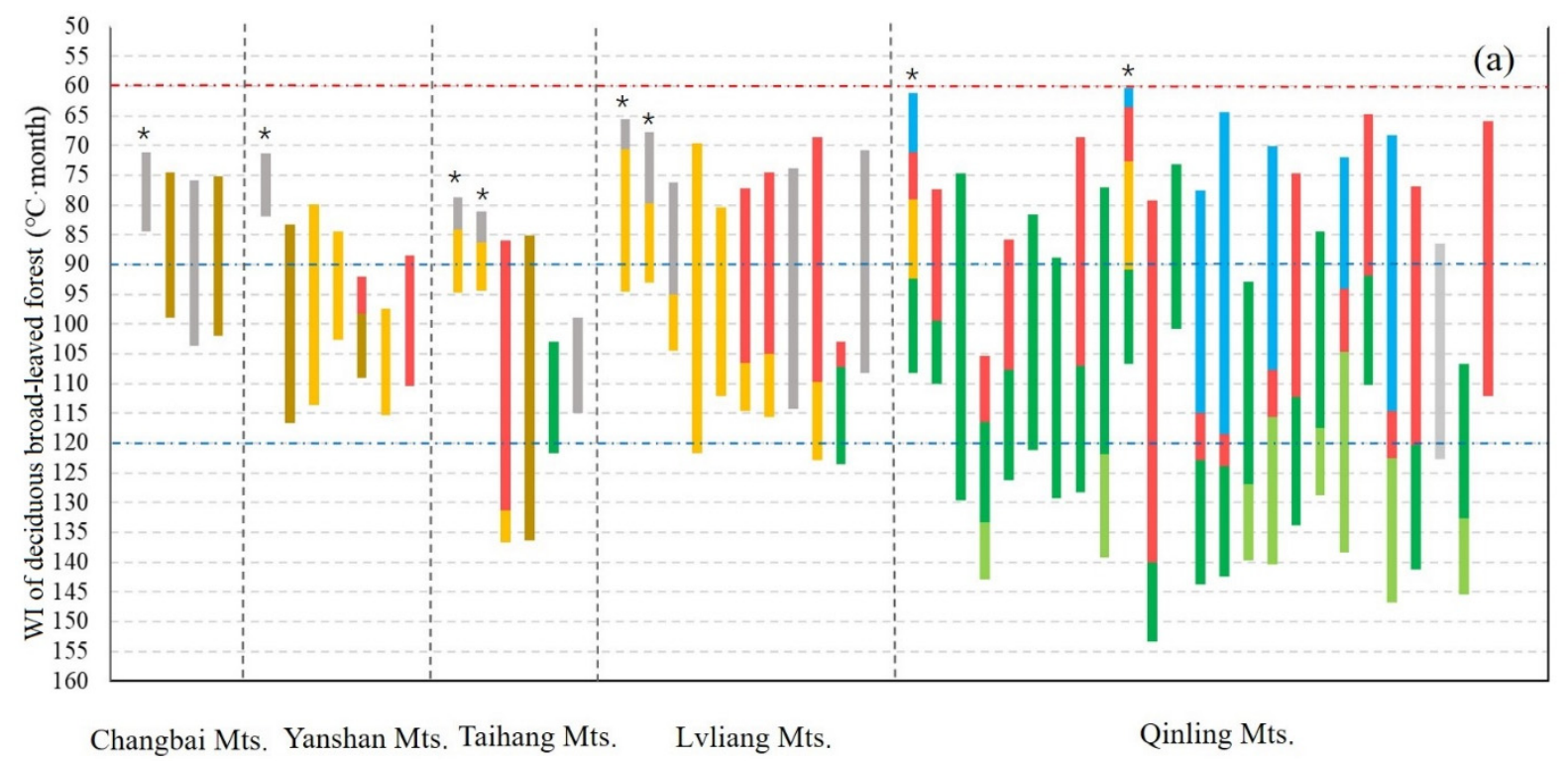

Figure 8. Cont. 


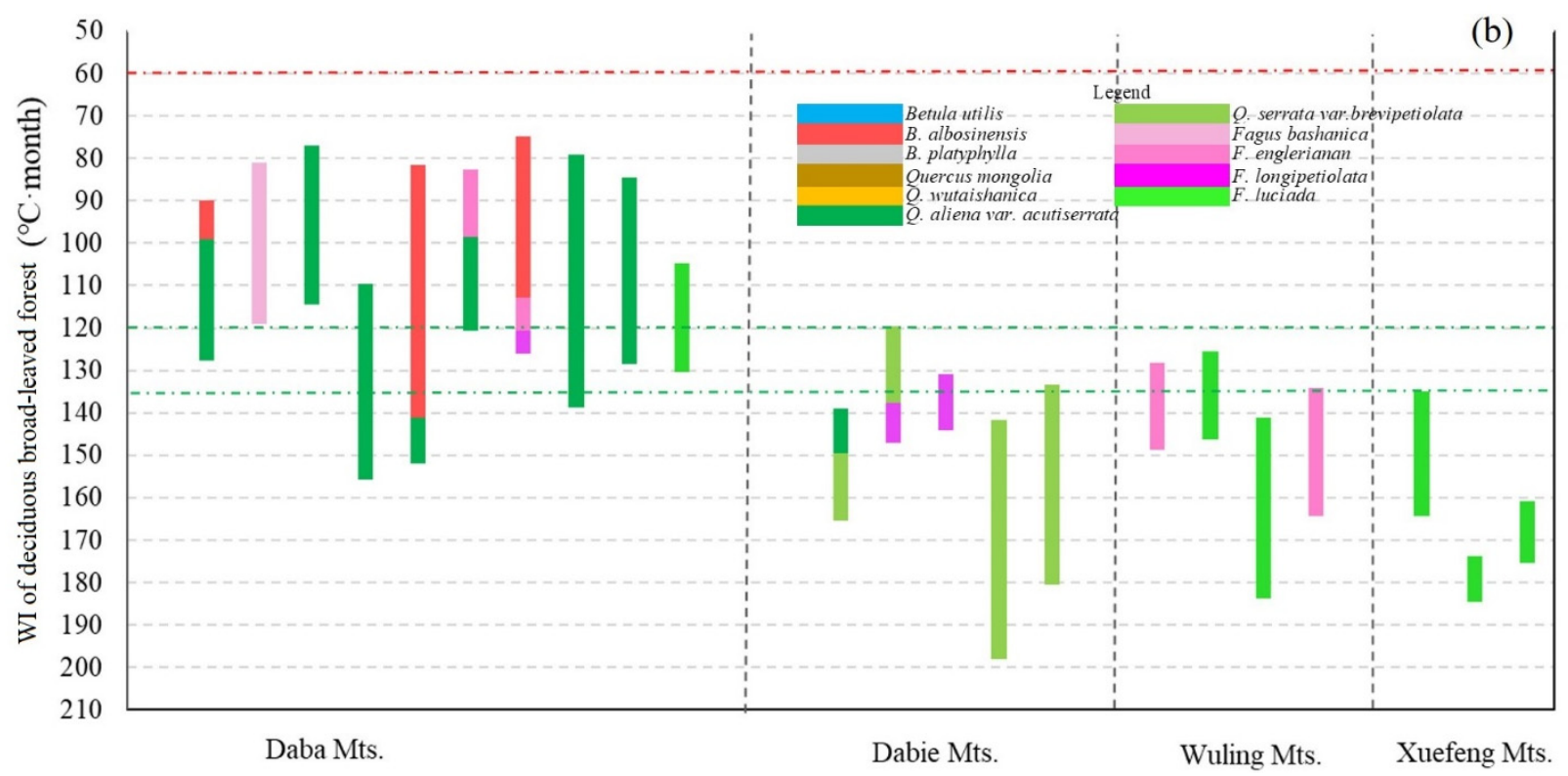

Figure 8. The warmth index (WI) of deciduous broad-leaved forest on the temperate mountains (a) and on the subtropical mountains (b) in the east monsoon realm of China. Bars with an asterisk represent the upper limits of deciduous broadleaved forest on the mountains with climatic treeline. Bars without asterisk represent the upper limits of deciduous broad-leaved forest on the mountains without climatic treeline, Mts., mountain range. ${ }^{*} p<0.05$.

Table 1. Hierarchical multiple regression summary for deciduous broad-leaved forest on the mountains without climatic treeline in the east monsoon realm of China.

\begin{tabular}{|c|c|c|c|c|c|c|c|c|c|c|}
\hline DV & Model & Adjusted $R^{2}$ & $\Delta R^{2}$ & $\Delta \mathrm{F}$ & Sig. $\Delta \mathrm{F}$ & Variables & B & $\beta$ & $T$ & $p$ \\
\hline UMDB(I) & 1 & 0.733 & 0.809 & 10.619 & 0.016 & $\begin{array}{l}\text { Intercept } \\
\text { MinT } \\
\text { PS }\end{array}$ & $\begin{array}{c}883.075 \\
40.224 \\
-10.266\end{array}$ & $\begin{array}{c}0.663 \\
-0.357\end{array}$ & $\begin{array}{c}6.035 \\
2.914 \\
-1.571\end{array}$ & $\begin{array}{c}0.002 \text { ** } \\
0.033 * \\
0.177\end{array}$ \\
\hline \multirow{3}{*}{ TMDB(II) } & 1 & 0.477 & 0.501 & 21.084 & $<0.001$ & $\begin{array}{c}\text { Intercept } \\
\text { MinT } \\
\text { PS }\end{array}$ & $\begin{array}{c}2827.668 \\
47.523 \\
-5.588\end{array}$ & $\begin{array}{c}0.538 \\
-0.257\end{array}$ & $\begin{array}{c}12.815 \\
4.206 \\
-2.008\end{array}$ & $\begin{array}{c}<0.001^{* * *} \\
<0.001^{* * *} \\
0.051\end{array}$ \\
\hline & 2 & 0.717 & 0.235 & 36.492 & $<0.001$ & $\begin{array}{c}\text { Intercept } \\
\text { MinT } \\
\text { PS } \\
\text { H }\end{array}$ & $\begin{array}{c}801.344 \\
34.165 \\
-0.713 \\
0.624\end{array}$ & $\begin{array}{c}0.387 \\
-0.033 \\
0.586\end{array}$ & $\begin{array}{c}2.150 \\
3.969 \\
-0.324 \\
6.041\end{array}$ & $\begin{array}{c}0.037^{*} \\
<0.001^{* * *} \\
0.748 \\
<0.001^{* * *}\end{array}$ \\
\hline & 3 & 0.793 & 0.076 & 16.217 & $<0.001$ & $\begin{array}{c}\text { Intercept } \\
\text { MinT } \\
\text { PS } \\
\text { H } \\
\text { RCT }\end{array}$ & $\begin{array}{c}935.613 \\
35.860 \\
-1.882 \\
0.413 \\
84.293\end{array}$ & $\begin{array}{c}0.406 \\
-0.087 \\
0.388 \\
0.325\end{array}$ & $\begin{array}{c}2.924 \\
4.871 \\
-0.989 \\
4.017 \\
4.027\end{array}$ & $\begin{array}{c}<0.006^{* *} \\
<0.001^{* * *} \\
0.329 \\
<0.001^{* * *} \\
<0.001^{* * *}\end{array}$ \\
\hline \multirow[b]{2}{*}{ SMDB(II) } & 1 & 0.289 & 0.357 & 5.265 & 0.015 & $\begin{array}{l}\text { Intercept } \\
\text { MinT } \\
\text { PS }\end{array}$ & $\begin{array}{c}214.362 \\
-32.936 \\
23.959\end{array}$ & $\begin{array}{c}-0.265 \\
0.408\end{array}$ & $\begin{array}{c}0.286 \\
-1.201 \\
1.849\end{array}$ & $\begin{array}{l}0.778 \\
0.245 \\
0.080\end{array}$ \\
\hline & 2 & 0.689 & 0.377 & 25.401 & $<0.001$ & $\begin{array}{c}\text { Intercept } \\
\text { MinT } \\
\text { PS } \\
\text { H }\end{array}$ & $\begin{array}{c}-416.691 \\
51.103 \\
14.449 \\
0.669\end{array}$ & $\begin{array}{l}0.411 \\
0.246 \\
0.991\end{array}$ & $\begin{array}{c}-0.815 \\
2.074 \\
1.646 \\
5.040\end{array}$ & $\begin{array}{c}0.426 \\
0.053 * \\
0.117 \\
<0.001 \text { *** }\end{array}$ \\
\hline
\end{tabular}


Table 1. Cont

\begin{tabular}{|c|c|c|c|c|c|c|c|c|c|c|}
\hline DV & Model & Adjusted $R^{2}$ & $\Delta R^{2}$ & $\Delta \mathrm{F}$ & Sig. $\Delta \mathrm{F}$ & Variables & $B$ & $\beta$ & $T$ & $p$ \\
\hline \multirow{5}{*}{ SMDB(II) } & \multirow{5}{*}{3} & \multirow{5}{*}{0.748} & \multirow{5}{*}{0.063} & \multirow{5}{*}{5.249} & \multirow{5}{*}{0.035} & Intercept & -491.184 & & -1.065 & 0.302 \\
\hline & & & & & & MinT & 82.399 & 0.663 & 3.165 & $0.006 * *$ \\
\hline & & & & & & PS & 13.306 & 0.227 & 1.682 & 0.111 \\
\hline & & & & & & $\mathrm{H}$ & 0.702 & 1.039 & 5.834 & $<0.001^{* * *}$ \\
\hline & & & & & & $\mathrm{RCT}$ & 68.807 & 0.339 & 2.291 & $0.035 *$ \\
\hline
\end{tabular}

Abbreviations: UMDB(I), the upper limit of deciduous broad-leaved forest on the mountains with climatic treeline in the east monsoon realm of China; TMDB(II), the upper limit of deciduous broad-leaved forest on the temperate mountains without climatic treeline; SMDB(II), the upper limit of deciduous broad-leaved forest on the subtropical mountains without climatic treeline; MinT, minimum temperature of the coldest month; PS, precipitation seasonality; DV, dependent variable; $\mathrm{H}$, peak elevation; $\mathrm{RCT}$, the rank in cold tolerance of species dominating the upper limit of montane deciduous broad-leaved forest; $\Delta R^{2}$, change of $R^{2} ; \Delta \mathrm{F}$, change of $\mathrm{F}$. $B$, unstandardized regression coefficients; $\beta$, standardized regression coefficients. Note: ${ }^{*} p<0.05,{ }^{* *} p<0.01,{ }^{* * *} p<0.001$.

Furthermore, the relative contributions of MinT and PS to the upper limit of MDB on the mountains with climatic treeline were $47.65 \%$ and $25.66 \%$, respectively. The elevation of the upper limit on the mountains with climatic treeline was positively correlated with MinT while it negatively correlated with PS. The relative contributions of MinT, PS, H, and RCT to the upper limit of MDB on the mountains without the climatic treeline in the temperate climate zone were $26.70 \%, 5.72 \%, 25.51 \%$, and $21.37 \%$, respectively; the elevation of the upper limit on mountains without the climatic treeline in the temperate climate zone was negatively correlated with PS, while it was positively correlated with all the other factors. The relative contribution rates of MinT, PS, H, and RCT to the upper limit of MDB on the mountains without the climatic treeline in the subtropical climate zone were $21.87 \%$, $7.49 \%, 34.27 \%$, and $11.18 \%$, respectively; the elevation of the upper limit on mountains without the climatic treeline in the subtropical climate zone was positively correlated with all the factors (Figure 9).

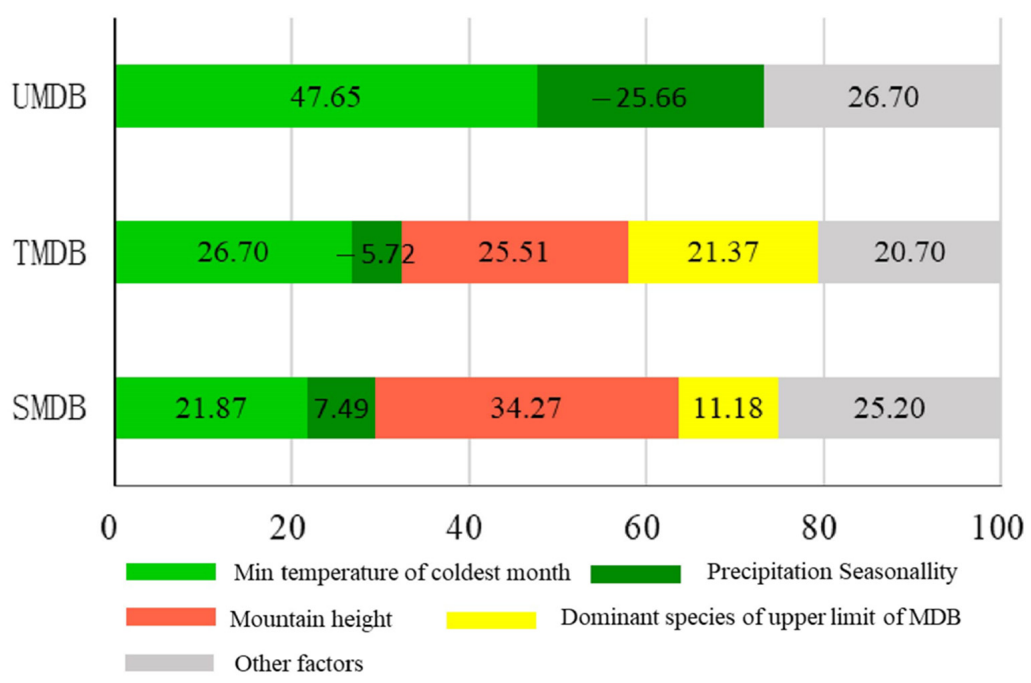

\section{Variation explained(\%)}

Figure 9. The relative contribution of environmental factors to the geographical pattern of the upper limit of montane deciduous broad-leaved forest in the east realm of China. UMDB, the upper limit of deciduous broad-leaved forest on the mountains with climatic treeline; TMDB, the upper limit of deciduous broad-leaved forest on the temperate mountains without climatic treeline; SMDB, the upper limit of deciduous broad-leaved forest on the subtropical mountains without climatic treeline. "-" in front of a number indicates that the independent variable was negatively correlated with the dependent variable; no sign in front of a number indicates that the independent variable was positively correlated with the dependent variable. 


\section{Discussion}

4.1. Dominant Factors Influencing the Upper Limit of Deciduous Broad-Leaved Forest on the Mountains with or without Climatic Treeline

Previous studies did not consider the effects of peak elevation and cold tolerance of dominant species on the upper limit of MDB, and proposed that climatic factors had great influences on the limits of montane vegetational belts [30,31]. Our results did not support the previous conclusions, and indicated that climatic factor was not a dominant factor influencing the upper limit of MDB on the mountain without climatic treeline. Körner (2012) found that a certain peak elevation is required for the actual treeline approaching the climatic treeline; while the upper limit of the deciduous broad-leaved forest on the mountain with topographical treeline (i.e., without climatic treeline) can be necessarily compressed to lower elevation by summit syndrome. Our result provided insight into the effect of peak elevation on the upper limit of MDB, and agreed with the conclusions reported based on European mountains [32,33], which suggested that the upper limit of MDB in the east monsoon realm of China can be divided into "true" and "false" limits [34]. The true upper limit of MDB represents that the dominant species of the upper limit of MDB have developed to the climatic threshold. On the contrary, the false upper limit of MDB represents that the dominant species of MDB cannot develop to its climatic threshold due to the influence of summit syndrome [19]. Therefore, the effect of climate on the upper limit of MDB mainly depends on the closeness between the climatic treeline and the actual treeline on the mountains. For example, the upper limit of deciduous broad-leaved forest, with B. albosinensis being the dominant species, is 2300 and $2600 \mathrm{~m}$ on the Tianhua and the Taibai mountains, respectively [35]. Both of them belong to the Qinling mountain ranges, and their climatic treeline is distributed within approximately $3400 \mathrm{~m}$ [36]. However, the peak of the Tianhua mountain is $2760 \mathrm{~m}$, while that of the Taibai mountain is $3767 \mathrm{~m}$ [37]. It was indicated that the low peak elevation of the Tianhua mountain depressed the upper limit of MDB to lower altitude, and prevented it from reaching the climatic threshold. Meanwhile, B. albosinensis, which is dominant species of MDB was distributed higher in the Taibai mountains than that in the Tianhua mountain, was able to develop to the climatic threshold. Moreover, the upper limit of MDB with B. utilis as the dominant species was distributed above the deciduous broad-leaved forest of B. albosinensis in the Taibai mountains, since the cold tolerance of $B$. utilis is greater than that of B. albosinensis [15]. It is indicated that the upper limit of MDB at the local scale can be modulated by the cold tolerance of dominant species of the upper limit of MDB.

Furthermore, this study found that the relative contribution of MinT to the upper limit of MDB was greater than that of PS, regardless of whether the actual treeline on the mountains was close to the climatic treeline or not. The result coincides with the quantitative analyses reported in earlier empirical studies, which concluded that MinT limited the upper limit of MDB on European mountains [14]. However, the low-temperature tolerance thresholds of the dominant species of MDB still need to be verified through plant physiological investigations. Moreover, the limits of MDB were also affected by biological factors, such as interspecific competition with coniferous species [38]. Several studies have pointed out that the upper limit of MDB is mainly affected by abiotic factors, such as climate and topography; the lower limit of MDB is primarily influenced by biological factors, such as interspecific competition and species dispersal [39]. Therefore, future studies that focus on quantifying the effects of biological factors on the limits of MDB might offer further insight into the biological mechanisms underlying the geographical pattern of MDB in the east realm of China.

\subsection{Dominant Factors Influencing the Upper Limit of MDB on Temperate and Subtropical Mountains without Climatic Treeline}

This study found that the upper limit of MDB on the temperate and subtropical mountains without climatic treeline was mainly affected by non-climate factors. However, the relative contribution of peak elevation to the effect of the upper limit of MDB on the 
subtropical mountains without climatic treeline was larger than that on the temperate mountains without climatic treeline. Wang (2004) pointed out that the elevation of the climatic treeline on the subtropical mountains of China ranges from 3600 to $4200 \mathrm{~m}$, and the average altitude of subtropical mountains is approximately $2200 \mathrm{~m}$. The height of climate treeline on the temperate mountain ranges from 3400 to $2000 \mathrm{~m}$, and the average elevation of temperate mountains is approximately $2400 \mathrm{~m}$ [35]. Furthermore, it is suggested that the difference between the peak elevation and climatic treeline on subtropical mountains is more significant than that on temperate mountains of China. Although climate is the direct factor affecting the limits of MDB, the peak elevation can indirectly affect the limits of MDB for climate varied with the mountain altitude [40]. Körner found that if peak elevation was significantly different from the climatic treeline, and even if the summit climate can support the growth of deciduous broad-leaved species, the latter cannot expand upwardly due to steep terrain and poor soil. The summit syndrome forces the upper limit of deciduous broad-leaved forest towards lower elevation [19]. Therefore, due to the substantially shortage of peak elevation on the subtropical mountains, the relative contribution of peak elevation to the upper limit of MDB is larger than that on the temperate mountains.

Furthermore, the current study showed that the upper limit of MDB on the temperate mountains without climatic treeline was negatively correlated with PS, while that on the subtropical mountains was positively correlated with PS. Shen (2015) found that the distribution of beech forests on the subtropical mountain was primarily related to the PS of monsoon climate [41]. Ge (2019) found that significant seasonal variation of precipitation on the subtropical mountains was beneficial to the development of deciduous oak forest, and the distribution of deciduous oak forest was usually higher than that of beech forest on the subtropical mountains [18]. Based on the above analysis, the increase in PS on subtropical mountains is favorable to forming the deciduous broad-leaved forest of the genus Quercus as the dominant species at a higher elevation, which lifts the upper limit of deciduous broad-leaved forest, causing a positive correlation between the upper limit of MDB and the PS of the subtropical mountain. However, the larger the seasonal variation of precipitation on the temperate mountains, the greater the probability of the presence of coniferous species [42]. It is suggested that the PS of temperate mountains is not conducive to the distribution of deciduous broad-leaved species, leading to a negative correlation between the upper limit of MDB and PS on the temperate mountain. At present, the difference in seasonal water requirements among different deciduous broad-leaved species is still unclear. Meanwhile, the physiological mechanism underlying the relationship between the upper limit of MDB and PS also needs to be further investigated.

\subsection{Difference of Dominant Species for the Upper Limit of Deciduous Broad-Leaved Forest on the Temperate and Subtropical Mountains}

Our results found that the dominant species of the upper limit of deciduous broadleaved forest on the temperate mountains were in genera Betula and Quercus, such as B. utilis, B. albosinensis, B. platyphylla, Q. mongolia, Q. wutaishanica, and Q. aliena var. acutiserrata; however, the dominant species of the upper limit of deciduous broad-leaved forest on the subtropical mountains were in the genera Fagus and Quercus. However, the upper limit of MDB with dominant Fagus species only distributes in the subtropical mountains of China, ranging from 27 to $30^{\circ} \mathrm{N}$. Beech forests mainly distribute in western Europe $\left(38\right.$ to $\left.58^{\circ} \mathrm{N}\right)$, the Appalachian Mountains of eastern North America $\left(20\right.$ to $\left.46^{\circ} \mathrm{N}\right)$, and Japanese islands ( 30 to $45^{\circ} \mathrm{N}$ ), with Fagus sylvatica, Fagus grandifolia, and Fagus crenata as the dominant species, respectively [43-45]. It is obvious that beech forests are absent in the vast temperate region of China, and their dominant species significantly varies among different continents in the world. The latitudinal range of the beech forest in China is the lowest, compared with that in the world. Hong (1993) indicated that the main factors limiting the northern boundary of the latitudinal distribution of the beech forest in western Europe were the mean temperature of the coldest month and the length of the growing season (no less than five months) [46]. Fang (2006) found that the northward distribution of the beech forest in North American and Japanese islands was limited by the warmth of growing 
season and low temperature in winter [44]. We also found that MinT limited the upper limit of beech forests. It is indicated that low winter temperature is the main factor affecting the upward and northward distributions of beech forests in China. Through comparing the arrival time of raining across the temperate and subtropical mountains in the east realm of China, Guo (2010) pointed out that although the temperature of temperate mountains had risen in spring, the raining areas moving from the southeast to the northwest could not reach the temperate mountains in time. The species of the genus Fagus prefer warm and humid climates, while beech forests are not distributed on the temperate mountains due to the little precipitation on the temperate mountains of China in spring [47].

\subsection{WI of the Upper Limit of MDB in the East Monsoon Realm of China}

WI can reflect the thermal characteristics of different vegetation types. Our results showed that the WI of the upper limit of deciduous broad-leaved forest on the mountains with climatic treeline was about $60^{\circ} \mathrm{C}$ month. The WI at the upper limit of deciduous broad-leaved forest on the mountains with climatic treeline was always lower than that on the mountains without climatic treeline, even with the same dominant species forming the upper limit of MDB on these mountains. According to Fang (2001), the WI at the northern boundary of latitudinal distribution of deciduous broad-leaved forest in China was $90^{\circ} \mathrm{C}$ month [23]. It is suggested that the WI at the upper limit of deciduous broad-leaved forest on mountains is lower than that at the northern boundary. Based on the geographical distribution of vegetation in China, the northern boundary of the latitudinal distribution of deciduous broad-leaved forests is along the northeast-southwest line of China, from Kaiyuan and Fuxin in Liaoning province, to Zhangjiakou in Hebei province [8]. The dominant species at the boundary is Quercus wutaishanica [48]. Our study found that the dominant species in the upper limit of MDB on the mountains with climatic treeline were B. utilis and B. platyphylla. The cold tolerance of B. utilis and B. platyphylla were greater than that of $Q$. wutaishanica [13]. Therefore, the differential cold tolerance of the dominant species could explain the lower WI at the upper limit of deciduous broad-leaved forest with altitudinal distribution than that at the northern boundary with latitudinal distribution.

\section{Conclusions}

The highest upper limit of MDB occurs on the Taibai peak of the Qinling mountain ranges, with an elevation of $2800 \mathrm{~m}$, and the WI at the highest upper limit of MDB is as low as $60^{\circ} \mathrm{C}$ month. Meanwhile, the effect of climate on the upper limit of MDB in the east monsoon realm mainly depends on the closeness between the actual and climatic treeline. The upper limit of MDB on the mountains with climatic treeline is mainly affected by climatic factors, while that on the mountains without climatic treeline is mainly affected by non-climatic factors (i.e., peak elevation and the cold tolerance of dominant species). Through evaluating the relative contribution of climatic factors, peak elevation, and cold tolerance of dominant species to the upper limit of MDB in the east monsoon realm of China, our study improves understanding of the differences in species composition across MDBs, providing climatic correlates for predicting the dynamics of the upper MDB forest communities under climate change.

Supplementary Materials: The following are available online at https:/ / www.mdpi.com/article/ 10.3390/f12091225/s1, Source data are provided with this paper. Table S1: The upper limit of deciduous broad-leaved forest on the mountains with climatic treeline in the east monsoon realm of China and their environmental variables. Table S2: The upper limit of deciduous broad-leaved forest on the temperate mountains without climatic treeline in the east monsoon realm of China and their environmental variables. Table S3: The upper limit of deciduous broad-leaved forest on the subtropical mountains without climatic treeline in the east monsoon realm of China and their environmental variables. Reference list: the geographical location and elevation of upper limit of deciduous broad-leaved forest on the mountains, the dominant species of montane deciduous broad-leaved forest, and the altitude of mountains with deciduous broad-leaved forest, were derived from these references. 
Author Contributions: B.Z. designed the study; J.W. and Y.Y. collected the data; J.W. did the analysis; B.Z. and J.W. wrote the manuscript. All authors have read and agreed to the published version of the manuscript.

Funding: This study was supported by the Science and Technology Basic Resources Investigation Program "Integrated Scientific Investigation of the North-South Transitional Zone of China" (Grant No. 2017FY100900).

Informed Consent Statement: This study did not involve humans.

Data Availability Statement: The data presented in this study are available in supplementary material.

Conflicts of Interest: The authors declare no conflict of interest.

\section{References}

1. Wu, Z.Y. Physical Geography of China: Plant Geography; Science Press: Beijing, China, 1983; pp. $20-45$.

2. Wen, D. Carbon Sequestration in Chinese Forest Ecosystems: Pattern, Potential, and Controlling Mechanisms; University of Chinese Academy of Sciences: Beijing, China, 2016; pp. 4-14.

3. Rahmat, A. Hydrological Characteristics under Deciduous Broadleaf and Evergreen Coniferous Forests in Central Japan. Int. J. Geomate 2019, 16, 217-224. [CrossRef]

4. Dai, J.H.; Cui, H.T. A review on the studies of alpine timberline. Sci. Geogr. Sin. 1999, 19, 243-249.

5. Ohsawa, M. An Interpretation of Latitudinal Patterns of Forest Limits in South and East Asian Mountains. J. Ecol. 1990, 78, 326-339. [CrossRef]

6. Irl, S.D.H.; Anthelme, F.; Harter, D.E.V.; Jentsch, A.; Lotter, E.; Steinbauer, M.J.; Beierkuhnlein, C. Patterns of island treeline elevation-A global perspective. Ecography 2015, 39, 427-436. [CrossRef]

7. Liu, Y.L.; Guo, R.Q.; Sun, S.C. Variations in the vertical vegetation zonation of subtropical Chinese mountains: The importance of climatic seasonality. Acta Ecol. Sin. 2010, 30, 3912-3922.

8. Xu, H.C. Natural Forests in North China; China Science and Technology Press: Beijing, China, 2003; pp. 1-10.

9. Chen, L.Z. Flora and Vegetation Geography of China; Science Press: Beijing, China, 2014; pp. 344-349.

10. Rumpf, S.B.; Hülber, K.; Klonner, G.; Moser, D.; Schütz, M.; Wessely, J.; Willner, W.; Zimmermann, N.E.; Dullinger, S. Range dynamics of mountain plants decrease with elevation. Proc. Natl. Acad. Sci. USA 2018, 115, 1848-1853. [CrossRef] [PubMed]

11. Gottfried, M.; Pauli, H.; Futschik, A.; Akhalkatsi, M.; Barančok, P.; Alonso, J.L.B.; Coldea, G.; Dick, J.; Erschbamer, B.; Calzado, M.R.F.; et al. Continent-wide response of mountain vegetation to climate change. Nat. Clim. Chang. 2012, 2, 111-115. [CrossRef]

12. Körner, C.; Basler, D.; Hoch, G.; Kollas, C.; Lenz, A.; Randin, C.F.; Vitasse, Y.; Zimmermann, N. Where, why and how? Explaining the low-temperature range limits of temperate tree species. J. Ecol. 2016, 104, 1076-1088. [CrossRef]

13. Sakai, A. Freezing tolerance of evergreen and deciduous broad-leaved trees in Japan with reference to tree regions. Low Temp. Sci. Ser. B Biol. Sci. 1979, 30,1-9.

14. Sakai, A.; Larcher, P.D.W. Frost Survival of Plants; Springer Science \& Business Media: Berlin, Germany, 1987; pp. 62-85. [CrossRef]

15. Lenz, A.; Hoch, G.; Vitasse, Y.; Körner, C. European deciduous trees exhibit similar safety margins against damage by spring freeze events along elevational gradients. New Phytol. 2013, 200, 1166-1175. [CrossRef]

16. Stephenson, N.L. Climatic control of vegetation distribution: The role of the water balance. Am. Nat. 1990, 135, 649-670. [CrossRef]

17. China Forest Editorial Board. Chinese Forest (Broadleaved Forest); China Forestry Press: Beijing, China, 2000; pp. $1838-1875$.

18. Ge, J. Climatic seasonality is linked to the occurrence of the mixed evergreen and deciduous broad-leaved forests in China. Ecosphere 2019, 10, e02862. [CrossRef]

19. Körner, C. Alpine Treelines: Functional Ecology of the Global High Elevation Tree Limits; Springer Science \& Business Media: Berlin, Germany, 2012; pp. 23-25.

20. Odland, A. Effect of latitude and mountain height on the timberline (Betula pubescens ssp. czerpanovii) elevation along the central Scandinavian mountain range. Fenn. Int. J. Geogr. 2015, 193, 261-270. [CrossRef]

21. Zhang, B.P.; Tan, J.; Yao, Y.H. Digital Integration and Patterns of Mountains Altitudinal Belts; China Environmental Science Press: Beijing, China, 2009; pp. 200-223.

22. Zhang, B.P.; Yao, Y.H. Studies on Mass Elevation Effect; China Environment Press: Beijing, China, $2015 ;$ pp. 9-27.

23. Fang, J.Y. Rediscussion about the forest vegetation zonation in eastern China. Acta Bot. Sin. 2001, 43, 522-533. [CrossRef]

24. Kang, M.Y.; Zhu, Y. Discussion and analysis on the geo-ecological boundary in Qinling Range. Acta Ecol. Sin. 2006, 27, 2774-2784.

25. Jobbágy, E.; Jackson, R. Global controls of forest line elevation in the northern and southern hemisphere. Glob. Ecol. Biogeogr. 2000, 9, 253-268. [CrossRef]

26. Ghalambor, C.K.; Huey, R.B.; Martin, P.R.; Tewksbury, J.J.; Wang, G. Are mountain passes higher in the tropics? Janzen's hypothesis revisited. Integr. Comp. Biol. 2006, 46, 5-17. [CrossRef]

27. Hijmans, R.J.; Cameron, S.E.; Parra, J.L.; Jones, P.G.; Jarvis, A. Very high resolution interpolated climate surfaces for global land areas. Int. J. Clim. 2005, 25, 1965-1978. [CrossRef] 
28. Elsen, P.R.; Monahan, W.B.; Merenlender, A.M. Global patterns of protection of elevational gradients in mountain ranges. Proc. Natl. Acad. Sci. USA 2018, 115, 6004-6009. [CrossRef]

29. Fang, J.Y.; Yoda, K. Climate and vegetation in China (I). Changes in the altitudinal lapse rate of temperature and distribution of sea-level temperature. Ecol. Res. 1988, 3, 37-51. [CrossRef]

30. Peng, B.Z.; Chen, F. Progress in the study of vertical mountain zonation in China. Sci. Geogr. Sin. 1999, 4, 303-308. [CrossRef]

31. Sun, J. Mountain altitudinal belt: A review. Ecol. Environ. Sci. 2014, 23, 1544-1550. [CrossRef]

32. Holtmeier, F.K.; Broll, G. Sensitivity and response of northern hemisphere altitudinal and polar treelines to environmental change at landscape and local scales: Treeline and environmental change. Glob. Ecol. Biogeogr. 2005, 14, 395-410. [CrossRef]

33. Grabherr, G.; Nagy, L.; Thompson, D. An Outline of Europe's Alpine Areas. In Alpine Biodiversity in Europe; Springer: Berlin/Heidelberg, Germany, 2003; pp. 3-12. [CrossRef]

34. Zhang, Q.; Du, J.H.; Tian, H.; Huang, Y.X. The temporal-spatial characteristics of the pseudo-timberline in Shimentain National Nature Reserve and its adjacent areas based on 3S technology. Trop. Geogr. 2018, 38, 364-371. [CrossRef]

35. Lei, M.D. Vegetation in Shanxi, China; Science Press: Beijing, China, 1999; pp. 410-440.

36. Wang, X.P.; Zhang, L.; Fang, J.Y. Relationship between alpine timberline and climate in China. Acta Geogr. Sin. 2004, 59, 871-879.

37. Li, Z.G.; Dang, K.L.; Li, D.W. Integrated Scientific Investigation of Tianhua Mountains in Shanxi Province; Shanxi Science and Technology Press: Shanxi, China, 2005; pp. 426-450.

38. Sundqvist, M.K.; Sanders, N.J.; Wardle, D.A. Community and ecosystem responses to elevational gradients: Processes, mechanisms, and insights for global change. Annu. Rev. Ecol. Evol. Syst. 2013, 44, 261-280. [CrossRef]

39. Fattorini, S.; Di Biase, L.; Chiarucci, A. Recognizing and interpreting vegetational belts: New wine in the old bottles of a von Humboldt's legacy. J. Biogeogr. 2019, 46, 1643-1651. [CrossRef]

40. Woodward, F.I.; Williams, B.G. Climate and plant distribution at global and local scales. Vegetatio 1987, 69, 189-197. [CrossRef]

41. Shen, Z.-H.; Fang, J.-Y.; Chiu, C.-A.; Chen, T.-Y.; Liu, H. The geographical distribution and differentiation of Chinese beech forests and the association with Quercus. Appl. Veg. Sci. 2014, 18, 23-33. [CrossRef]

42. Amissah, L.; Mohren, G.M.J.; Bongers, F.; Hawthorne, W.D.; Poorter, L. Rainfall and temperature affect tree species distribution in Ghana. J. Trop. Ecol. 2014, 30, 435-446. [CrossRef]

43. Fang, J.Y.; Guo, Q.H.; Liu, G.H. Distribution patterns of Chinese Beech (Fagus L.) species in relation to topography. Acta Bot. Sin. 1999, 41, 766-774. [CrossRef]

44. Fang, J.; Lechowicz, M.J. Climatic limits for the present distribution of beech (fagus L.) species in the world. J. Biogeogr. 2006, 33, 1804-1819. [CrossRef]

45. Cai, Q.; Welk, E.; Ji, C.; Fang, W.; Sabatini, F.M.; Zhu, J.; Zhu, J.; Tang, Z.; Attorre, F.; Campos, J.A.; et al. The relationship between niche breadth and range size of beech (Fagus) species worldwide. J. Biogeogr. 2021, 48, 1240-1253. [CrossRef]

46. Hong, B.G.; An, S.Q. Preliminary studies on the geographical distribution of Fagus in China. J. Integr. Plant Biol. 1993, 35, $229-233$.

47. Guo, K.; Werger, M.J.A. Effect of prevailing monsoons on the distribution of beeches in continental East Asia. For. Ecol. Manag. 2010, 259, 2197-2203. [CrossRef]

48. Wu, Z.Y. Vegetation of China; Science Press: Beijing, China, 1980; pp. 250-280. 